ARTIGO ORIGINAL

\title{
Lembranças sobre a educação física escolar: uma narrativa de estudantes de educação física
}

\section{Memories about school physical education: a narrative of physical education students}

Diego Grasel Barbosa ${ }^{1}$, Raísa Carvalho da Silva ${ }^{1}$, Marcelo Dutra Della Justina ${ }^{2}$, Geraldo José Ferrari Junior ${ }^{1}$, Gelcemar Oliveira Farias ${ }^{1}$, Érico Pereira Gomes Felden ${ }^{1}$

${ }^{1}$ Universidade do Estado de Santa Catarina (UDESC), Florianópolis/SC, Brasil

${ }^{2}$ Universidade Federal de Santa Catarina (UFSC), Florianópolis/SC, Brasil

\section{HISTÓRICO DO ARTIGO \\ Recebido: 08 abril 2020}

Aprovado: 18 maio 2020

\section{PALAVRAS-CHAVE:}

Educação Física; Capacitação Profissional; Percepção; Narrativas Pessoais.

\section{KEYWORDS:}

Physical Education;

Inservice Training; Perception;

Personal Narratives.

\section{RESUMO}

OBJETIVO: Descrever as narrativas de estudantes de Educação Física de uma universidade pública do sul do Brasil sobre as retrospectivas da Educação Física escolar no ensino fundamental.

METODOS: Participaram do estudo 239 estudantes que responderam a um questionário com questões sócio demográficas e questões referentes às percepções e lembranças sobre as experiências da Educação Física no Ensino Fundamental.

RESULTADOS: A partir das narrativas percebeu-se que os investigados consideraram as experiências na educação física escolar mais positivas que negativas, dando valor à diversificação de conteúdos e à relação positiva com o professor. Por outro lado, os acadêmicos com percepção negativa, se referiram às aulas monótonas, sentimentos de vergonha e exclusão e desvalorização da disciplina.

CONCLUSÃO: Pode-se concluir que a investigação permite ampliar e promover novas discussões sobre o desenvolvimento e formação profissional para a atuação na área da Educação Física escolar.

\section{ABSTRACT}

OBJECTIVE: To describe the retrospective narratives of Physical Education in the Elementary School of graduate students of Physical Education of a public university in southern Brazil.

METHODS: The study included 239 students of both sexes. The academics answered a questionnaire with socio-demographic questions and questions regarding the perceptions and memories about the experiences of Physical Education in Elementary Education.

RESULTS: From the narratives, it was noticed that the academics who considered the experiences more positive than negative gave value to the diversification of contents and to the positive relation with the teacher. On the other hand, academics with a more negative perception, referred to the monotonous classes, feelings of shame and exclusion and devaluation of the discipline.

CONCLUSION: This study opens the door to new discussions about the importance of the quality of development and professional training for the area of Physical Education in schools. 


\section{INTRODUÇÃO}

A Educação Física, mediante a sua inserção na escola, busca a obrigatoriedade nos currículos e nas propostas curriculares, além da legitimação e do reconhecimento neste cenário. Estudos com diferentes bases epistemológicas vêm debatendo sobre o papel desta disciplina como componente curricular e sobre os desafios do professor para se adequar aos parâmetros pedagógicos das escolas (CRUM, 2017; DE CASTRO, 2017; HESS; NEIRA; TOLEDO, 2018). Essa discussão não é centrada apenas no papel do professor no ambiente escolar, mas sobre o lugar da Educação Física no processo de hierarquização das disciplinas. Neste sentido, os questionamentos sobre a inserção e a valorização da Educação Física perpassam por inúmeros pontos, destacando-se as questões relacionadas a infraestrutura da escola, a avaliação diferenciada e valorização do professor (CRUM, 2017).

Como forma de legitimar a Educação Física na escola, alguns currículos regionais apresentam a noção de cultura nas propostas pedagógicas, considerando relevante que as questões da multiculturalidade sejam compartilhadas nas propostas curriculares (NEIRA NUNES, 2011). Betti et al. (2014) consideraram que um grande desafio da Educação Física é a articulação dos currículos na educação básica que sistematizem, em termos de conteúdo, as estratégias, a avaliação e a formação de sujeitos emancipados e autônomos, capazes de exercitar a crítica no âmbito da cultura de movimento. Para isso, segundo estes autores se faz necessária uma Educação Física que busque: educar os alunos para as dimensões éticas e políticas; ensinar considerando as idiossincrasias; e fomentar as possibilidades de autoconhecimento e comunicação.

Porém, a falta de critérios avaliativos ou a falta de diálogo entre professor e aluno com relação à forma como estes serão avaliados ao final dos bimestres, pode contribuir para a deterioração da imagem e percepção mais negativa desta disciplina pelos alunos ao longo dos anos escolares (DOS SANTOS; MAXIMIANO, 2013). Com relação à satisfação das aulas da educação física, Brandolin, Koslinski e Soares (2015) verificaram que alunos com altas habilidades, que praticavam esporte fora da escola apresentaram mais chances de estarem satisfeitos com as suas experiências passadas na disciplina do que seus homólogos com baixa ou média habilidade esportiva e que não praticavam atividades ou esportes fora da escola. Além disso, acredita-se que implicações positivas de conhecimentos adquiridos na Educação Física escolar possam fomentar percepções mais positivas e servir como fonte de motivação e incentivo para o ingresso no curso superior de Educação Física.

A motivação para o ingresso no curso de Educação Física pode estar relacionada pela à lembrança positiva da intervenção de um professor (FOLLE et al., 2009), ou a memória de ter um professor da educação física escolar como um exemplo (BACK et al., 2019). E enquanto imerso em cursos de licenciatura em Educação Física, experiências com a escola no contexto da formação acadêmica, podem indicar o desejo de realização pessoal e profissional e de continuidade na profissão pelos estudantes (SAMPAIO et al., 2019). Por outro lado, aulas de educação física escolar com professores desmotivados podem despertar percepções negativas, com uma compreensão reducionista da área, repercutindo negativamente para as esco-
Ihas profissionais no futuro. Assim, faz-se importante investigar qualitativamente quais elementos das aulas de educação física escolar contribuem para percepções positivas ou negativas na vida adulta de acadêmicos de diferentes fases de cursos de Educação Física no ensino superior.

Assim, argumenta-se que as experiências significativas e boas práticas proporcionadas pela educação física escolar podem ser ricas e auxiliar diretamente na escolha da formação profissional e no desenvolvimento pessoal dos sujeitos. Desta forma, explorar as lembranças relacionadas a este período é relevante, visto que se torna possível compreender os fatores que levam os acadêmicos de Educação Física a perceberem as suas experiências com a disciplina no tempo escolar. Frente a isso, o objetivo do presente estudo foi descrever as narrativas de estudantes de Educação Física de uma universidade pública do sul do Brasil sobre as retrospectivas da educação física escolar no ensino fundamental.

\section{MÉTODOS}

A investigação tratou-se de um estudo descritivo, com abordagem qualitativa e quantitativa dos dados e com delineamento transversal (THOMAS; NELSON; SILVERMAN, 2009), desenvolvido a partir do projeto de pesquisa "Estudo longitudinal da saúde e cognição de acadêmicos de Educação Física de uma universidade pública do sul do Brasil", aprovado pelo Comitê de Ética em Pesquisa com Seres Humanos desta universidade (Parecer no 83.192/2012).

O estudo foi conduzido em uma universidade pública na cidade de Florianópolis-SC, no primeiro semestre do ano de 2017. Nesse período, havia na instituição 478 estudantes matriculados nas oito fases dos cursos de bacharelado e licenciatura em Educação Física (237 do bacharelado e 241 da licenciatura), e todos foram considerados elegíveis para participar do estudo. Todos os estudantes foram convidados a participar voluntariamente, que totalizou 239 estudantes, sendo 124 da Licenciatura e 115 estudantes do Bacharelado.

Como critério de inclusão foram considerados, aqueles que estavam presentes em sala de aula no momento da coleta de dados e aceitaram participar voluntariamente, assinando o Termo de Consentimento Livre e Esclarecido (TCLE). Aqueles que não foram encontrados em nenhum dos dias de coleta não fizeram parte do estudo. Para garantir o anonimato dos participantes do estudo, ao transcrever as narrativas, foram utilizados nomes fictícios. Além dos nomes fictícios, os participantes foram numerados.

O questionário entregue aos acadêmicos foi constituído por questões sociodemográficas e questões relacionadas com as percepções referentes às experiências nas aulas de educação física no ensino fundamental. Com relação às questões sociodemográficas, os participantes deveriam indicar o sexo (masculino ou feminino), o ano de conclusão do Ensino Médio e o curso (Licenciatura ou Bacharelado em Educação Física).

$O$ enunciado da pergunta relativa às percepções referentes às experiências nas aulas de educação física no ensino fundamental era: "De forma geral as suas experiências nas aulas de educação física no ensino fundamental foram:" a) "mais positivas que negativas" e b) "mais negativas que positivas". Para esta questão, o participante deveria indicar qual a opção melhor 
refletia a sua opinião sobre as experiências pregressas na educação física no ensino fundamental. Além disso, por meio de uma questão aberta, os participantes descreveram as principais lembranças da educação física escolar com o seguinte enunciado: "Quais suas principais lembranças da educação física no ensino fundamental?".

De posse dos questionários preenchidos a análise dos dados qualitativos foi realizada por meio da análise de conteúdo de acordo com as três fases propostas por Bardin (2011): a) pré-análise, b) exploração do material e c) tratamento, inferência e interpretação dos resultados. Na pré-análise, os pesquisadores organizaram e sistematizaram os materiais disponíveis para o estudo, ou seja, as duas questões abertas dos questionários. Assim, foi realizada a "leitura flutuante" das respostas, a fim de conhecer e obter algumas impressões dos documentos. E após manipular diversas vezes os documentos, os autores realizaram recortes de trechos considerados importantes para discussão.

$\mathrm{Na}$ exploração do material, os autores contaram as ideias e as palavras que se repetiram com maior frequência e as transcreveram para um documento do Microsoft Word, com o cuidado de separar as palavras mais frequentes em cada uma das seguintes categorias: 1) percepções mais positivas; 2 ) percepções mais negativas. Em cada uma das categorias citadas acima, foram elaboradas nuvens de palavras por meio do site "WordArt.com".

Após separar e ilustrar as palavras mais frequentes baseadas em cada uma das categorias assinaladas pelos sujeitos no questionário, foram formadas a unidades de registro que permitiram traçar o perfil dos sujeitos pesquisados. Desta forma, com base nas palavras mais frequentes foram formadas as seguintes unidades de registro: "conteúdos e características das aulas", "professores" e "sentimentos".

Por fim, para análise das respostas abertas, foi realizado o tratamento, inferência e interpretação dos resultados. Neste sentido, foi feito o levantamento das categorias a partir das unidades de registro pré-estabelecidas para o estudo. Assim, para cada uma das unidades de registro e percepções positivas/ negativas no ensino Fundamental, foram transcritos os trechos com maior pertinência e adequação.

A análise dos dados quantitativos foi utilizada a estatística descritiva (média, desvio-padrão e distribuição de frequências) no programa estatístico SPSS, versão 20.0 , adotando- se nível de significância de $5 \%$.

\section{RESULTADOS}

A seguir os dados são apresentados primeiramente de forma estatística e posteriormente de forma qualitativa. As características gerais da amostra foram apresentadas na Tabela 1. A amostra geral apresentou média de idade de $22,21(5,20)$ anos e foi composta, em sua maioria, por estudantes do sexo masculino $(58,2 \%)$ e que estudavam curso de Licenciatura $(51,9 \%)$. Além disso, verificou-se que em sua maioria os sujeitos apresentaram percepções mais positivas $(68,9 \%)$ que negativas $(31,1 \%)$ das aulas de educação física no ensino fundamental (Tabela 1).

A percepção mais positiva verificada na maioria dos

${ }^{1}$ Ver em: Wordart.com estudantes investigados vai ao encontro do estudo de Brandolin, Koslinski e Soares (2015), no qual observaram que $78,2 \%$ dos alunos do ensino médio estavam satisfeitos com a disciplina. Apesar de ser amostra diferente supõe-se que a alta satisfação destes alunos implique também em percepções mais positivas que negativas acerca desta disciplina.

Tabela 1. Características sociodemográficas da amostra $(n=239)$.

\begin{tabular}{lc}
\hline Variáveis & Índices $(\mathbf{n}, \%)$ \\
\hline Sexo & $139(58,2 \%)$ \\
Masculino & $100(41,8 \%)$ \\
Feminino & \\
Curso & $124(41,9 \%)$ \\
Licenciatura & $115(48,1 \%)$ \\
Bacharelado & $22,21 \pm 5,20$ \\
Idade*(anos) & \\
Percepções Ensino Fundamental & $164(68,9 \%)$ \\
Mais positivas que negativas & $74(31,1 \%)$ \\
Mais negativas que positivas &
\end{tabular}

*Valores descritos em média e desvio padrão para a variável idade. Fonte: Os autores, 2018.

\section{Experiências mais positivas no ensino fundamental}

Conforme ilustrado na Figura 1, foram observadas as palavras que apareceram com maior frequência (tamanhos maiores) e menores frequências (tamanhos menores) nos relatos dos estudantes que apresentaram experiências mais positivas na educação física do ensino fundamental. Dentre as palavras que apareceram com maior frequência destacaram-se: "variedade de modalidades", "olímpiadas", "brincadeiras", "esportes", "competições", "bom professor", "quarteto fantástico", dentre outras (Figura 1).

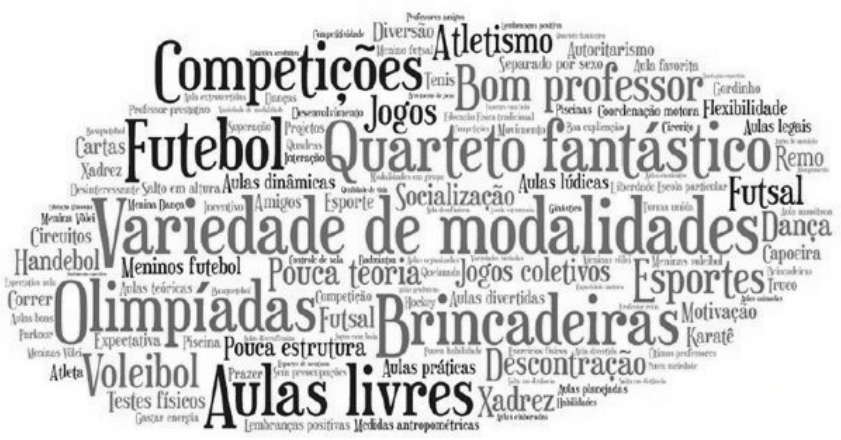

Figura 1. Frequência de palavras relacionadas às experiências positivas no Ensino Fundamental oriunda das narrativas. Fonte: Os autores, 2018.

\section{Conteúdos e características das aulas}

Foi possível verificar que as percepções positivas sobre a disciplina se dão pelo trabalho de diferentes modalidades esportivas e conteúdos interdisciplinares. Como por exemplo, ob- 
servou-se que os estudantes relataram grande importância às atividades lúdicas, jogos, brincadeiras, variedade de modalidades, campeonatos, jogos coletivos, dança e xadrez. Além disso, eles relataram lembranças de que as aulas eram dinâmicas, lúdicas, divertidas e livres.

A tríade pessoa, ambiente e tarefa é discutida nas investigações sobre o desenvolvimento motor, porém como analisou-se apenas o ambiente e as modalidades envolvidas nessa construção recordatória da Educação Física, foi possível observar a prática estruturada como decisiva para experiências mais positivas na aquisição de habilidades motoras. Neste sentido, Rosário e Darido (2012), discutem sobre a importância da sistematização dos conteúdos da Educação Física na escola para a possibilidade de refletir sobre a própria prática, melhorar o planejamento das atividades e melhorar as condições de aprendizagem dos alunos.

Além disso, de acordo com Betti e Ziuliani (2002), nos anos iniciais do Ensino Fundamental (1으 ao 5 ano), é preciso levar em conta a atividade corporal como elemento fundamental da vida infantil, e que uma estimulação psicomotora diversificada apresenta profundas relações com o desenvolvimento cognitivo, afetivo e social da criança. Esta diversificação na oferta de um grande repertório de atividades pode incidir positivamente na percepção dos próprios alunos, como no caso do estudo de Freitas et al. (2016), no qual foi verificada uma participação ativa e positiva de alunos do 5 ano do Ensino Fundamental I, retratando a relevância e atratividade da disciplina de Educação Física para os participantes.

A diversificação dos conteúdos, foi relatada por João (18) em jogos/brincadeiras, diferentes modalidades, experiências em esportes, judô, surfe, skate, dança, rugby, etc.", por Larissa (20) que elencou "algumas experiências diferentes (tênis, hockey, etc.)" e por Alfredo (23) que apontou a presença de "muitos fundamentos dos esportes com bola, além de aulas de atletismo e regras." Além disso, Guilherme (21) e Amanda (19), relembraram configurações de que a "as aulas eram divertidas com participação de todos" e que as "aulas eram animadas com muitas brincadeiras e futebol" respectivamente. Abaixo foram transcritos alguns outros trechos que caracterizaram os sujeitos com percepção mais positiva relacionadas aos conteúdos e características das aulas:

"Vivências em diversos esportes, até aquáticos, e de aventura [...] Diversas práticas em relação à saúde e das modalidades esportivas em geral" (Tamires, 23)

"Foi fundamental para o meu desenvolvimento. Percebi claramente o quanto a pratica dessas modalidades principalmente da ginástica olímpica foram importantes na graduação durante as aulas práticas" (Isabela, 21)

"A aula era dinâmica com muita presença de jogos. Brincadeiras como pega-pega e queimada eram presentes nas aulas. De forma geral eu gostava" (Raimundo, 25).

Outra questão observada nas narrativas relacionadas aos conteúdos e características das aulas daqueles acadêmicos com percepção mais positiva foi o valor atribuídos às competições escolares (olímpiadas). Conforme exemplifica Reverdito et al. (2008), os eventos esportivos podem promover valores ao ser humano a partir das virtudes educativas existentes na competição pedagógica. Dentre elas é possível citar, cooperação, autonomia, intenções educativas nas competições, valores sociais e motivacionais. Foi possível perceber a importância dos jogos escolares para as experiências mais positivas da acadêmica Silvia (19):

"Todas as aulas de educação física eram muito legais e as melhores lembranças são dos jogos coletivos que eu participava representando a escola pelo munícipio. Participação no moleque bom de bola" (Silvia, 19).

Sendo assim, percebe-se que as competições escolares têm um grande potencial educativo aos alunos, devendo ser explorada da maneira correta com vistas a evitar demasiada competitividade sem algum fim educacional.

\section{Professor}

Nesta unidade de registro os acadêmicos valorizaram a figura do professor como referência de boas aulas. Para Cotrim et al. (2011), os professores de Educação Física devem propiciar atividades com objetivos definidos e direcionados para o desenvolvimento de aspectos específicos dos alunos. A atuação do professor com base em conteúdo, oportunidades de inúmeras vivências motoras, instrução apropriada, além de melhores condições de infraestrutura e de materiais e equipamentos, produz efeitos diferentes no desenvolvimento motor de crianças.

No que tange ao papel do professor de educação física no ensino fundamental, Oliveira e Alves (2005) ao realizarem entrevistas semiestruturadas com cinco professoras, abordando temas da formação, concepções sobre "bons e maus alunos" e definições sobre estimulação e motivação, verificaram que "bom professor" é aquele que tem sua interação com o estudante marcada pela afetividade, valorização da sua individualidade e pela dedicação ao trabalho. Sugere-se que estudantes que tiveram bons professores na educação física escolar, apresentam mais chances de construírem percepções mais positivas referentes às experiências nesta disciplina.

Neste sentido, Kátia (18) e Marisa (19) descreveram que "o professor era muito bom no controle da sala e na explicação e aplicação de atividades e as diversificava" e que "o professor era bem capacitado e explorava bastante diferentes tipos de atividades [...]" respectivamente. Além disso, Alexandre (20) narrou as suas lembranças da seguinte forma: "As melhores possíveis, sempre fazia todas as aulas, era muito próximo do professor de educação física e me auxiliava sempre que precisava." Diante das respostas é identificável que para os estudantes a ideia de bom professor está associada ao conhecimento e à interação entre professor e aluno.

Em estudo de Triani, Junior e Novikoff (2017), com objetivo de identificar e analisar algumas das representações sociais possíveis que estudantes do curso de Educação Física apresentam sobre a formação de professores, os autores verificaram, que a caraterística mais marcante do bom professor de Educação Física é o conhecimento. No entanto, vale ressaltar que a interação entre professor e aluno com ênfase na construção de vínculos afetivos no processo de ensino e aprendizagem é uma das características mais relevantes do bom professor (DE CARVALHO; ROLÓN; MELO, 2018).

Levando-se em consideração a influência da capacitação e qualificação dos professores na construção de experiências positivas relacionadas à educação física escolar que futuramente podem vir a repercutir na escolha da profissão, destacaram-se 
a narrativa de Olívia (23) na qual apontou: "Tive ótimos professores ao longo da vida escolar o que me motivou a seguir a carreira na área." E de Juliana (21):

"Ouso dizer que minha educação física no ensino fundamental foi de grande importância para a minha escolha para o curso superior. Visitei minha professora para agradecer os exemplos" (Juliana, 21).

Entende-se desta forma, que as motivações no processo de escolha profissional estão, em geral, estão vinculadas às experiências e vivências que o indivíduo realiza dentro do próprio processo de desenvolvimento. É nesta perspectiva, que em estudo de Back et al. (2019), com objetivo de investigar os saberes e motivações para a formação inicial de estudantes do curso de Licenciatura em Educação Física, a partir das vivências pregressas e do início do curso, os autores destacaram os fatores da presença de um professor na família, o gosto pelo esporte, ter diploma de nível superior, vivência no esporte, gosto pelo ensino e a referência de um professor de Educação Física na escola como um exemplo.

\section{Sentimentos}

Os sentimentos têm sido amplamente debatidos no contexto da educação física escolar, visto que a afetividade considerada a partir da teoria Walloniana é bastante relevante na construção do indivíduo (aluno) de forma integral e completa (VASQUE; GARANHANI, 2016). A interação entre professor e aluno pode gerar tanto benefícios para o processo de ensino aprendizagem como também rupturas. A afetividade atua de várias formas na educação física escolar, como por exemplo, no grau de excitação somática, nas características individuais, na satisfação com a tarefa, nas frustações, na exposição do aluno, na alegria e na tristeza (FERREIRA, 2010).

Para Ferreira (2010), a prática de conteúdos como jogos, esportes, danças e ginasticas são consideradas como um campo extremamente fértil para as mais diversas formas de manifestações emocionais e afetivas. O ambiente das aulas é, portanto, um ambiente de atitudes e comportamentos que favorece o aluno a externalizar o que está sentindo, valorizando a socialização e a interação de forma a interferir na construção do aluno como ser humano. Abaixo foram observados trechos das narrativas que enfatizaram os sentimentos positivos referentes à educação física no ensino fundamental. São elas:

"Momento de diversão e descontração com os amigos sem preocupar-se com a nota ou desempenho. As olimpíadas eram o marco da diversão" (Romeu, 18).

"Lembro de me divertir muito, contava as horas para que as aulas de educação física começassem. Era um tempo muito bom em que as olimpíadas escolares eram muito aguardadas (Ícaro, 22).

"A educação física era uma das minhas matérias favoritas. Era sempre divertida e esperada. E sempre ficava irritado no dia que tinha aula e chovia" (Bruno, 19).

A partir das narrativas, percebe-se sentimentos importantes de expectativa, descontração e euforia para o momento da aula de educação física. Os sentimentos positivos relacionados às aulas ajudam a explicar a preferência que os alunos têm desta disciplina com relação às demais. Freitas et al. (2016) verificaram que a Educação Física além de ser a disciplina preferida, ficou entre as três disciplinas mais importantes na percepção de alunos do 5o ano do Ensino Fundamental I de São Paulo.

\section{Experiências negativas no ensino fundamental}

Conforme ilustrado na Figura 2, foram observadas as palavras que apareceram com maior frequência (tamanhos maiores) e menores frequências (tamanhos menores) nos relatos dos sujeitos que apresentaram percepções negativas frente às experiências da educação física no ensino fundamental. Dentre as palavras que apareceram com maior frequência destacam-se: "aulas livres", "futsal", "quarteto fantástico", "pouca variedade" e "aulas monótonas".

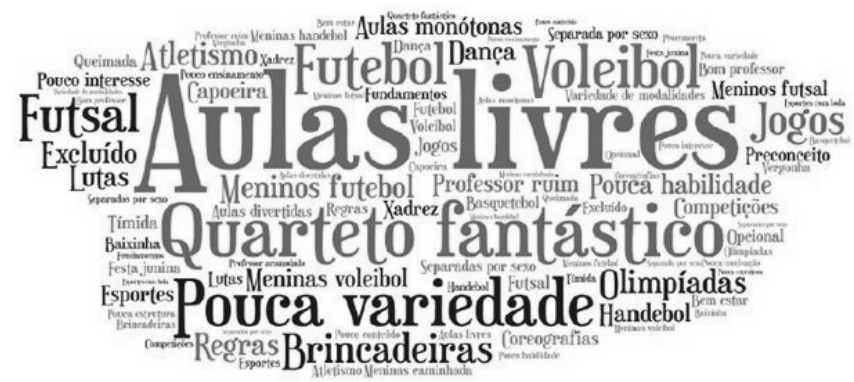

Figura 2. Frequência de palavras relacionadas às experiências negativas no Ensino Fundamental oriunda das narrativas. Fonte: Os autores, 2018

\section{Conteúdos e características das aulas}

Os sujeitos com percepção mais negativa do que positiva das aulas, relataram que a escassez da variedade de atividades e aulas pouco interessantes foram decisivas para percepção negativa, tal como pode ser observado no relato de Freddy (23) no qual escreveu sobre a lembrança de "visão esportiva limitada à apenas alguns esportes" e de Matheus (22) de que a aula era caracterizada "[...] basicamente por futebol e quando possuía estagiários, eles apresentavam outros esportes". Além disso, Elisa (22) descreveu que o conteúdo da disciplina era composto pelo "quarteto fantástico, aulas livres, sem nenhuma atividade proposta. Meninos jogavam futebol e meninas vôlei" e Vanessa (24) que "as aulas só tomavam algum outro rumo, caso houvesse algum evento na escola (festival de dança, festa junina, etc.)". Na narrativa abaixo pode-se perceber a baixa infraestrutura disponibilizada para a prática da Educação Física:

"Aulas que não possuíam interação, somente os meninos jogavam e sempre futsal, as meninas ficavam sentadas olhando na maioria das vezes, quando possível jogávamos vôlei em um canto do estacionamento da escola" (Rosa, 22).

Foram observados ainda inúmeros relatos de percepção negativa referentes as aulas livres, em que muitas vezes possivelmente ela não apresentava direcionamento e planejamento pedagógico adequado.

No que tange ao ensino tradicional dos esportes, Folle, Pozzobom e Brum (2008), verificaram que apesar dos professores possuírem tendências voltadas ao ensino tradicional dos jogos esportivos, os alunos sentiram-se satisfeitos com as aulas de educação física. No entanto, quando as aulas não tomam direcionamento algum, deixando os alunos livres para brincarem e 
jogarem, as mesmas podem influenciar negativamente na percepção e satisfação dos alunos.

Tais percepções negativas foram observadas nos relatos de Robson (21) no qual destacou "as aulas livres dadas pelos professores", de Humberto (21) "do professor jogar a bola e sentar", de Laura (21) sobre "as aulas livres com pouco ensinamentos" e de Emília (24) no qual identificou que os conteúdos das aulas se resumiam em "Futebol para quem jogava e uma bola de vôlei para o resto." De forma semelhante, Rômulo (19) trouxe a lembrança de "aula monótona no qual a maior parte das aulas eram vôlei para as meninas e futebol para os meninos." Outros relatos referentes às percepções negativas sobre conteúdos e características das aulas foram transcritos abaixo:

"A aula era basicamente feita de queimada e das quatro modalidades mais utilizadas (basquetebol, futebol, handebol e voleibol)" (Pedro, 21).

"Em quase todas as aulas acontecia o futebol porque o professo deixava livre para os alunos escolherem. Quem não participava, jogava vôlei, bambolê etc." (Camila, 16).

Ainda consoante, as lembranças negativas, Odilon (18) discorreu sobre a falta de instrução na aula, ilustrada no seguinte relato: "O professor levava as bolas e nós escolhíamos o que jogar. Raramente ele nos instruía”.

\section{Professor}

$\mathrm{Na}$ análise dos dados, foi verificada diferente postura do professor frente a alunos em diferentes estágios de aprendizagem. E ainda no mesmo discurso, foi relatado que o professor que ministrava a disciplina não apresentava formação em Educação Física:

"O professor sempre colocava todas as meninas que tinham mais jeito no outro time, e deixava todas as que tinham mais dificuldade no meu e ainda roubava na arbitragem. Ele não era formado em Educação Física" (Vitória, 21).

Assim, ressalta-se a importância da formação e desenvolvimento profissional em educação física para aulas com maior fundamentação teórica, com o objetivo de propiciar e promover o desenvolvimento integral dos alunos. Para discutir sobre a importância da formação do professor de Educação Física é relevante ressaltar seu papel dentro da escola. Nunes e Rúbio (2008) refletem acerca da frequente insatisfação por parte dos professores de Educação Física que atuam na escola quanto às suas aulas, a desmotivação dos alunos, às condições de trabalho e, principalmente, a confusão e a indefinição da função social da educação física escolar. Corroborando com esta ideia, em estudo de Etchepare, Pereira e Zinn (2008), no qual os autores verificaram a opinião dos professores sobre a atuação do profissional de educação física nos anos iniciais do ensino fundamental, foi verificado que $93,75 \%$ dos professores entrevistados apontaram como imprescindível a atuação do profissional formado em Educação Física nas séries iniciais.

\section{Sentimentos}

No tocante aos sentimentos, verificaram-se que estudantes com mais dificuldades nas aulas de educação física, se percebiam com menor interação social do professor e colegas e por vezes acabavam excluídos de algumas atividades como foram observados nas narrativas de Moisés (19) em que "não costumava frequentar as aulas por não ter habilidade e não me interessava pelos esportes aplicados", de Alex (24): "Eu era gordo e acabava excluído de algumas atividades", de Emanuelle (26) que "não frequentava as aulas porque ninguém jogava comigo por não ter habilidade" e de Gabriel (27): "Lembro que não ia bem na educação física porque era gordinho, então não era muito bom nos esportes [...]". Além disso, Tobias (23) considerou sentimentos negativos quando se colocava no lugar dos colegas como observada na narrativa abaixo:

"São boas (as lembranças), porém as pessoas que tinham mais dificuldade, não recebiam o devido apoio necessário e muitas vezes acabavam se sentindo excluídas e inferiores [...]" (Tobias, 23).

Fischer (2009) indica que as aulas de Educação Física nunca devem ser excludentes, com desmerecimento dos menos habilidosos, e muito menos seletivas, com exigência e valorização do desempenho dos estudantes. É preciso que o professor promova e estimule a participação de seus estudantes frente às situações que eles julguem vergonhosas, refletindo as causas de sua manifestação e desenvolvendo sua autoconfiança e auto eficácia, que se apresentam como importante inibidores do sentimento de vergonha. De acordo com a teoria da autoeficácia de Bandura (1997), pode-se prever melhor a maneira como os indivíduos agirão por meio de suas crenças em suas capacidades do que pelo que realmente são capazes de realizar, pois as percepções de auto eficácia ajudam a determinar o que os indivíduos fazem com os conhecimentos e habilidades que possuem. Assim, considera-se importante que o professor de Educação Física contribua para o fortalecimento das crenças dos alunos em suas capacidades de realizar determinadas habilidades com sucesso.

Deste modo, ressalta-se a importância do professor de Educação Física em entender que em uma mesma turma existem inúmeras características singulares que diferenciam aqueles com mais dificuldades daqueles com menos dificuldades, tanto em termos de realização das atividades quanto em questões psicológicas como autoestima, autoconceito e auto eficácia.

\section{CONCLUSÃO}

Considerando as narrativas dos estudantes de Educação Física, sobre as retrospectivas da educação física escolar no ensino fundamental, foram observadas tanto lembranças positivas quanto negativas referente às aulas de educação física na escola. Foram verificados pontos positivos como a abordagem de conteúdos diversificados e interdisciplinares, além de sentimentos de expectativa e euforia para a participação das aulas e a percepção de professores comprometidos com a profissão. Já os pontos negativos abarcaram algumas problemáticas referente ao baixo repertório de conteúdo ministrado, professores desmotivados e sentimentos de exclusão. Para que haja mudança em um cenário desfavorável que fortaleçam lembranças e sentimentos negativos que os alunos carregam sobre a Educação Física, são necessárias modificações nos cursos de formação inicial e na atuação dos profissionais da área.

Vale frisar que por se tratar de lembranças que induziram os sujeitos a escreverem sobre suas percepções acerca das experiências na educação física escolar, muitas vezes o que alguns jul- 
garam como positivo pode ter sido julgado como negativo para outros. No entanto, considerou-se que pela amostra ter sido composta por acadêmicos de Educação Física, em processo de formação profissional e que discutem frequentemente o papel do profissional de Educação Física na escola e demais contextos da área, estes possuem posturas críticas e reflexivas quanto as suas lembranças das experiências na educação física no ensino fundamental. Conclui-se, que o presente estudo abrirá portas para novas discussões sobre a importância da qualidade do desenvolvimento e formação profissional para a área da Educação Física, em especial no âmbito escolar.

\section{REFERÊNCIAS}

BACK, A. V.; SILVA JUNIOR, A. P.; AHLERT, A.; SAMPAIO, A. A. Saberes que motivam na formação inicial em educação física. Caderno de Educação Física e Esporte, Marechal Cândido Rondon, v. 17, n. 1, p. 45-52, 2019.

BANDURA, A. Self-efficacy: the exercise of control. New York: Freeman, 1997.

BARDIN, L. Análise de conteúdo. Lisboa: Edições 70, 2011.

BETTI, M.; KNIJNIK, J.; VENÂNCIO, L.; NETO, L. S.; DAOLIO. Fundamentos filosóficos e antropológicos da Teoria do Se-movimentar e a formação de sujeitos emancipados, autônomos e críticos: o exemplo do currículo de Educação Física do Estado de São Paulo. Movimento, Porto Alegre, v. 20, n. 4, p. 1631-53, 2014.

BETTI, M.; ZULIANI, L. R. Educação física escolar: uma proposta de diretrizes pedagógicas. Revista Mackenzie de Educação Física e Esporte, São Paulo, v. 1, n. 1, p. 73-81, 2002.

BRANDOLIN, F.; KOSLINSKI, M.; SOARES, A. J. G. A percepção dos alunos sobre a educação física no ensino médio. Journal of Physical Education, Maringá, v. 26, n. 4, p. 601-10, 2015.

COTRIM, J. R.; LEMOS, A. G.; JÚNIOR, N.; EVANGELISTA, J.; BARELA, J. A. Desenvolvimento de habilidades motoras fundamentais em crianças com diferentes contextos escolares. Journal of Physical Education, Maringá, v. 22 , n. 4 , p. $523-33,2011$

CRUM, B. A crise de identidade da educação física. Ensinar ou não ser, eis a questão. Boletim Sociedade Portuguesa de Educação Física, Linda-a-Velha, v. 1, n. 7-8, p. 133-48, 2017.

DE CASTRO, V. G. As atribuições da Educação Física escolar: um enfoque especial no Ensino Médio. Motrivivência, Florianópolis, v. 29, n. 52, p. 12435, 2017.

DOS SANTOS, W.; DE LIMA MAXIMIANO, F. Memórias discentes em educação física na educação básica: práticas avaliativas. Movimento, Porto Alegre, v. 19, n. 2, p. 79-101, 2013.

ETCHEPARE, L. S.; PEREIRA, E. F.; ZINN, J. L. Educação física nas séries iniciais do Ensino Fundamental. Journal of Physical Education, Maringá, v. 14, n. 1, p. 59-66, 2008.

FERREIRA, R. E. A educação física escolar e sua relação com a aprendizagem e as emoções dos alunos no ensino fundamental. 2010. 120f. Dissertação (Mestrado em Educação) - Universidade Federal de Juiz de Fora, Juiz de fora, 2010.

FISCHER, F. Estados emocionais e educação física escolar: considerações iniciais à luz de uma psicologia bioecológica. 2009. 68f. Trabalho de Conclusão de Curso (Bacharelado em Educação Fìsica) - Universidade Estadual Paulista "Júlio de Mesquita Filho", Rio Claro, 2009.

FOLLE, A.; FARIAS, G. O.; BOSCATTO, J. D.; DO NASCIMENTO, J. V. Construção da carreira docente em educação física: escolhas, trajetórias e perspectivas. Movimento, Porto Alegre, v. 15, n. 1, p. 25-49, 2009.

FOLLE, A.; POZZOBON, M. E.; BRUM, C. F. Modelos de ensino, nível de satisfação e fatores motivacionais presentes nas aulas de educação física. Journal of Physical Education, Maringá, v. 16, n. 2, p. 145-54, 2008.

FREITAS, J. F.; SILVA, J. E. B.; LACERDA, M. R. A.; LEONARDI, T. J. A identidade da Educação Física escolar sob o olhar dos alunos do 5a ano do ensino fundamental I. Pensar a Prática, Goiânia, v. 19, n. 2, p. 396-409, 2016.

HESS, C. M.; NEIRA, M.; TOLEDO, E. O papel do professor de educação física nos anos iniciais nas escolas estaduais de ensino integral do estado de São Paulo. Movimento, Porto Alegre, v. 24, n. 4, p. 1155-66, 2018.

NEIRA, M. G.; NUNES, M. L. F. Contribuciones de los estudios culturales para el currículo de la educación física. Revista Brasileira de Ciências do Esporte, Florianópolis, v. 33, n. 3, p. 671-85, 2011.

NUNES, M. L. F.; RÚBIO, K. Currículo (s) da educação física e a constituição da identidade de seus sujeitos. Currículo Sem Fronteiras, São Paulo, v. 8, n. 2, p. 55-77, 2008

OLIVEIRA E. C. B.; ALVES, P. B. Ensino fundamental: papel do professor, motivação e estimulação no contexto escolar. Paidéia, Ribeirão Preto, v. 15, n. 31 , p. $227-238,2005$

REVERDITO, R. S.; SCAGLIA, A. J.; DA SILVA, S. A. D.; GOMES, T. M. R.; DE LIMA PESUTO, C.; BACCARELLI, W. Competições escolares: reflexão e ação em pedagogia do esporte para fazer a diferença na escola. Pensar a Prática, Goiânia, v. 11, n. 1, p. 37-45, 2008.

ROSÁRIO, L. F. R. DARIDO, S. C. Os conteúdos escolares das disciplinas de história e ciências e suas relações com a organização curricular da educação física na escola. Revista Brasileira de Educação Física e Esporte, São Paulo, v. 26, n. 4, p. 691-704, 2012

SAMPAIO, A. A.; BAEZ, M. A. C.; STOBAUS, C. D.; OLIVEIRA, J. R. G. Realização e desenvolvimento pessoal e profissional em licenciandos de educação física. Caderno de Educação Física e Esporte, Marechal Cândido Rondon, v. 17, n. 1, p. 53-60, 2019.

THOMAS, J. R.; NELSON, J. K.; SILVERMAN, S. J. Métodos de pesquisa em atividade física. Porto Alegre: Artmed Editora, 2009

TRIANI, S. F.; JÚNIOR, C. A. O. M.; NOVIKOFF, C. As representações sociais de estudantes de educação física sobre a formação de professores. Movimento, Porto Alegre, v. 23, n. 2, p. 575-86, 2017.

\section{AGRADECIMENTOS}

Os autores agradecem à Promop/Udesc (Programa de Bolsas de Monitoria de Pós-Graduação) e à Coordenação de Aperfeiçoamento de Pessoal de Nível Superior (Capes) pela concessão de bolsas de pós-graduação.

\section{CONFLITO DE INTERESSE}

Os autores do estudo declaram não haver conflito de interesses.

\section{FINANCIAMENTO}

Este estudo não recebeu apoio financeiro.

\section{ORCID E E-MAIL DOS AUTORES}

Diego Grasel Barbosa

ORCID: 0000-0002-5543-5445

E-mail: diegograsel1987@gmail.com

Raísa Carvalho da Silva

ORCID: 0000-0002-5963-816X

E-mail: rahisac@gmail.com

Marcelo Dutra Della Justina

ORCID: 0000-0001-9301-9808

E-mail: marcelo.ddj@hotmail.com

Geraldo Jose Ferrari Junior

ORCID: 0000-0002-9739-3220

E-mail: geraldo ferrari@hotmail.com

Gelcemar Oliveira Farias

ORCID: 0000-0003-3552-3437

E-mail: fariasgel@hotmail.com

Érico Pereira Gomes Felden

ORCID: 0000-0002-6924-122X

E-mail: ericofelden@gmail.com 